\title{
ESTÁGIO CURRICULAR SUPERVISIONADO COMO PRÁXIS: ALGUMAS PERGUNTAS E POSSÍVEIS DE RESPOSTAS
}

\author{
SUPERVISED CURRICULAR STAGE AS PRÁXIS: SOME QUESTIONS AND POSSIBLE ANSWERS \\ ESTUDIO CURRICULAR SUPERVISADO COMO PRÁXIS: ALGUNAS PREGUNTAS Y POSIBLES DE \\ RESPUESTAS
}

\author{
ARAÚJO, Osmar Hélio Alves ${ }^{1}$ \\ MARTINS, Elcimar Simão²
}

\begin{abstract}
RESUMO
Neste artigo, por meio de pesquisa de natureza teórica, problematizamos o estágio supervisionado nos cursos de licenciatura a partir da compreensão de estágio como subsídio da profissionalidade docente e intervenção política no contexto social. Problematizamos também, a partir de uma pesquisa documental com foco na análise do edital Capes $n^{\circ} 6 / 2018$, como essas questões são consideradas pela "nova" Política Nacional de Formação de Professores, especificamente o Programa de Residência Pedagógica (PRP). Sugere-se que o estágio possibilite a compreensão crítico-reflexiva do contexto escolar com sua diversidade cultural e social.
\end{abstract}

Palavras-chave: Estágio supervisionado. Formação de professores. Praxis.

\section{ABSTRACT}

In this article, we problematize supervised internships in undergraduate courses from the understanding of internships as a subsidy for teaching professionalism and political interventions in the social context. We also question how these issues are considered by the "new" National Teacher Education Policy, specifically the Pedagogical Residency Program (PRP), through Capes no. 6/2018 and 7/2018, under the government of Michel Temer. It is suggested that internships allow for the criticalreflective understanding of the school context alongside its cultural and social diversity.

Keywords: Supervised internships. Teacher training. Praxis.

\section{RESUMEN}

En este artículo problematizamos las prácticas docentes supervisadas en las carreras de licenciatura a partir de la comprensión de las prácticas como subsidio de la profesionalidad docente e intervención política en el contexto social. Problematizamos también cómo estas cuestiones son consideradas por la "nueva" Política Nacional de Formación de Profesores, específicamente en el Programa de Residencia Pedagógica (PRP), a través de las convocatorias Capes $n^{\circ}$ 6/2018 y n 7/2018, en el gobierno de Michel Temer. Se sugiere que las prácticas docentes posibiliten la comprensión crítico-reflexiva del contexto escolar con su diversidad cultural y social.

Palabras clave: Prácticas docentes supervisadas. Formación de Profesores. Praxis

\footnotetext{
1 Universidade Federal do Sul e Sudeste do Pará (UNIFESSPA), Marabá - PA - Brasil

2 Universidade da Integração Internacional da Lusofonia Afro-Brasileira - UNILAB - Ceará - Brasil
} 


\title{
PROPÓSITOS DO TEXTO
}

\begin{abstract}
「...1 talvez o que melhor defina a vida de um ser humano qualquer não são suas resnostas. mas as nerduntas due carreda nas costas. As nerduntas levam o homem a husc.ar. enrinuecer. preocunar-se. ocubar-se. cuidar. dialocar. escutar. e doar-se. Já as resnostas - sobretudo se as levamos demasiadamente a sério. definitiva e neremntoriamente. fechando-nos nara não ouvir outras tentativas de resnostas e nerduntas diferentes - correm muito mais o risco de paralisar, congelar, fechar e impor. (RIOS, 2014, p. 117)
\end{abstract}

Perguntas abrem caminhos que nos levam a "novas" respostas, a novos conhecimentos e, sobretudo, que exigem de nós uma atitude crítico-reflexiva diante da realidade social real. Perguntas também nos levam a construir outras perguntas que, muitas vezes, nascem de um percurso consubstanciado na reflexão sobre o contexto existente e que urge ser transformado. As respostas a estas perguntas se traduzem na busca por mudanças e transformações do status quo.

Como afirma Larrosa (2003, p.19), "O estudo se inicia perguntando e termina perguntando. Estudar é caminhar de pergunta em pergunta até as próprias perguntas. Sabendo que as perguntas são infinitivas e inapropriáveis". A partir de um diálogo com perguntas, (possíveis) respostas e novas indagações, este texto, em uma perspectiva teórica, se propõe a problematizar o estágio supervisionado nos cursos de licenciatura, seus elementos teórico-metodológicos, contextuais e históricos na formação docente, a partir da compreensão de estágio como subsídio da profissionalização docente (práxis) e instrumento de intervenção política no contexto social. De maneira geral, a partir de uma pesquisa documental com foco na análise do edital Capes $n^{\circ}$ 6/2018 , problematizamos também como essas questões são (ou não) consideradas pela "nova" Política Nacional de Formação de Professores, especificamente o Programa de Residência Pedagógica (PRP), no governo do Michel Temer 4 .

Apresentamos neste texto, a princípio, as questões: como fazer para que o estágio não redunde em mero ativismo a serviço da manutenção do atual estado de coisas? É possível fazer algo de concreto para alterar substancialmente o atual panorama do estágio nas licenciaturas? $\mathrm{O}$ que se espera da Residência Pedagógica na formação dos professores?

Este texto está organizado em duas seções. Primeiramente, discorremos sobre o estágio, a Pedagogia e a Didática como campos indissociáveis e como práxis emancipadoras. Em seguida, problematizamos as possibilidades de pensar a articulação entre universidade, estágio supervisionado e Educação Básica como espaços de formação de/para todos. Argumentamos que o estágio supervisionado é, em especial, o ponto de referência e convergência do currículo dos cursos de licenciatura porque, atrelado à pesquisa e aos demais componentes curriculares, é, acima de tudo, práxis que contribui e fomenta a construção da identidade docente dos futuros professores.

Vivemos hoje, sobretudo no contexto brasileiro, um momento que exige mais do que nunca uma educação que suscite questionamentos, reflexão-crítica e resistência. Necessita-se de uma

\footnotetext{
3 Dito edital regulamenta a chamada pública para a apresentação de propostas ao Programa de Residência Pedagógica (PRP). Disponivel em:<http://www.capes.gov.br/educacao-basica/programa-residencia-pedagogica>. Acesso em: 21 abr. 2018.

${ }^{4}$ No que segue, visando tornar a leitura fluída e agradável, optamos pela sigla "PRP" para fazer referência à Política Nacional de Formação de Professores com Residência Pedagógica.
} 
formação docente que se transforme em compromisso e ação política que vise (trans) formar não apenas os professores e as suas práticas no contexto escolar, como se isso bastasse para a transformação da sociedade.

Em muitos ditames constitucionais que são base para a formação dos professores no Brasil, os elementos teórico-metodológicas, em relação ao trabalho docente, são opacos. Como exemplo, segundo Libâneo (2006) e Pimenta et al. (2017), verificam-se nas Diretrizes Curriculares Nacionais para o Curso de Graduação em Pedagogia, licenciatura, visões simplificadas em relação ao campo da Pedagogia, da atividade docente, da unidade teoria e prática na formação dos professores, assim como ambiguidades no tocante à atuação do Pedagogo.

No tocante ao PRP, e às ações da Política Nacional de Formação de Professores ${ }^{5}$ do governo do Michel Temer, percebe-se uma proposta de reformulação (leia-se adequação) do estágio supervisionado, dos currículos e propostas pedagógicas dos cursos de licenciatura, visando articulá-los às orientações da $\mathrm{BNCC}^{6}$ (ANFOPE, 2017).

Práticas de formação docente e suas diretrizes, quando vazias das teorias pedagógicas e não comprometidas com as dimensões epistemológica, social, política e ética do trabalho docente, dizem da não qualidade da educação brasileira e do seu não efetivo compromisso com a realidade existencial da vida humana. A formação dos professores, por isso, não é um processo que acontece de modo alheio à realidade social, política e cultural real. Em uma mesma perspectiva, a ação docente não pode ficar restrita ao contexto escolar, presa a uma espécie de vai e vem entre diagnóstico, planejamento e ação, mas deve se envolver politicamente na realidade existencial visando a transformá-la. Em outras palavras, o papel do professor não se esgota na ação pedagógica nos contextos escolares, mas, ao contrário, é uma ação político-pedagógica contínua de comprometimento, promoção, defesa e cuidado com o desenvolvimento humano nos diferentes espaços da sociedade.

Assim, na contramão do PRP como a mera hora da prática, o estágio é, antes de tudo, práxis. O estágio tem o papel de provocar, suscitar a reflexão-crítica e oferecer aos estudantes as condições teórico-metodológicas para que se tornem senhores das suas práticas e formação, construtores da sua identidade profissional e conscientes do compromisso político da docência na sociedade de modo global.

\footnotetext{
5 Entre as medidas anunciadas no governo do Michel Temer, que são partes constituintes dessa "nova" política de formação docente, destacamos: a Base Nacional Docente; a Educação à Distância; o Prouni Ampliado e o Programa de Residência Pedagógica.

${ }^{6}$ Trata-se da Base Nacional Comum Curricular (BNCC) instituída através da Resolução CNE/CP n 2, de 22 de dezembro de 2017.
} 


\section{ESTÁGIO SUPERVISIONADO, A PEDAGOGIA E A DIDÁTICA EM UMA PERSPECTIVA DIALÓGICA}

A proposta desta seção é problematizar o estágio, sua relação com a Pedagogia e a Didática, e o seu papel na formação do professor, analisando-o numa perspectiva crítica de educação. Ao conduzirmos essa problematização, as primeiras perguntas que vem à tona são estas: o que é educação? O que é formação docente? O que é estágio? A educação é um processo de emancipação política; prática da liberdade; democratização do acesso aos bens culturais e coletivamente produzidos e para além da reprodução ideológica. É ainda a fonte mais plena e a razão do agir, do fazer pedagógico e do próprio existir do estágio na formação dos professores.

A educação é um processo permanente, contínuo e ininterrupto ao longo de toda a vida, com foco, sobretudo, na promoção de igualdade e dignidade humana; assim como é um processo que visa a construção de uma sociedade democrática, multicultural e solidária. Trata-se, segundo Shulman (2014), da compreensão de uma educação humanista abrangente. Ou seja, o "[...] essencial na educação [é]: a formação da pessoa humana, para além da instrumentalização competente do indivíduo capaz" (BRANDÃO, 2012, p. 46). Consubstanciado nessas ideias, compreendemos a formação docente como um processo que prepara os professores para a ação de ensinar a partir da mobilização dos alunos para a construção de saberes e a apreensão ${ }^{7}$ dos conhecimentos construídos pelas gerações. A formação docente, nesta perspectiva, consiste em fomentar a mobilização de saberes e a socialização de práticas significativas que contribuirão para a construção de uma escola verdadeiramente como espaço pedagógico-formativo docente-discente.

A formação dos professores, por isso, não é um processo que se pauta na racionalidade técnica que, muitas vezes, considera os professores como meros executores de decisões alheias, mas, ao contrário, deve ser compreendida e construída como um processo que os reconhece como sujeitos capazes de decidir, construir e transformar. A formação docente é, assim, uma célula viva construída e em construção, a partir da qual o processo educativo deve alcançar cada vez mais êxito à medida que essa formação auxilia os professores na construção da práxis partindo da leitura crítica da realidade, visando a transformá-la.

A educação e a formação dos professores são processos sociais e, por isso, práxis emancipatória. O estágio, como processo formativo, também não pode ser compreendido como algo deslocado do contexto social a partir do qual (ou não) as práticas docentes se materializam. O estágio, a Pedagogia e a Didática, entre outras áreas da ciência que auxiliam o fenômeno educativo, constituem um todo indissociável.

Estudos e pesquisas de Pimenta (2006), Franco (2012, 2014); Libâneo (2014); Pimenta e Almeida (2014), André (2012, 2016), e o exercício docente no Ensino Superior, mais precisamente no campo da pesquisa em educação e com foco na Pedagogia, na Didática e no estágio supervisionado, permitem-nos enfatizar que a Pedagogia, como ciência da educação que se volta essencialmente para a práxis educativa, possui gramática própria, clara epistemologia de inclusão, de emancipação do

\footnotetext{
7 Neste texto, optamos pelo uso do verbo apreender, em detrimento de aprender, pois [...]; para apreender é preciso agir, exercitar-se, informar-se, tomar para si, apropriar-se, entre outros fatores" (ANASTASIOU, 2003, p. 19).
} 
homem e de transformação do meio social. A Didática, por sua vez, está voltada para a fundamentação e compreensão do ensino.

Não podemos, por isso, pensar o estágio em separado da Pedagogia e da Didática, já que não é um processo que se constitui e se justifica em si e por si. São todos componentes constitutivos de uma mesma ciência, a Pedagogia, "que organiza ações estruturais, que produzam novas condições de exercício pedagógico, compatíveis com a expectativa da emancipação da sociedade; [e] procura [...] ampliar o conhecimento sobre a práxis educativa" (RIOS, 2014, p. 109).

A ausência da Pedagogia enfraquece o estágio como processo de formação, emancipação e práxis. É por meio da Pedagogia que o professor criticamente amplia e constrói conhecimento acerca da práxis educativa. Por isso, os estudantes não somente encontram na Pedagogia e na Didática aporte teórico, mas aprendem a ressignificar o estágio e adocência por meio de um exercício crítico, construtivo e emancipador. Sem o estágio, os estudantes, na maioria das vezes, têm dificuldades para compreender o real sentido político-pedagógico da docência e da escola.

Essa concepção faz emergir algumas perguntas: que sujeito (docente/discente) o estágio deve ajudar a formar? Que prática docente os estudantes devem construir e a serviço de quê e de quem? Como o estágio pode contribuir com os estudantes em face das contradições postas à docência?

A partir das contribuições de Almeida e Pimenta (2014); Pimenta e Lima (2017), argumentamos ser o estágio um processo que busca formar um profissional da educação com sensibilidade pedagógica para captar as diferentes realidades que perpassam o interior das escolas brasileiras; assumir os diversos encargos sociais da profissão; desenvolver a consciência inerente à responsabilidade dos profissionais da educação com a transformação da sociedade e com o fortalecimento, cuidado e resgate da dignidade e da qualidade de vida de todos os indivíduos. Entendemos, portanto, que o estágio é um instrumento político não somente para inserção dos estudantes no contexto escolar, mas, sobretudo, de responsabilidades compartilhadas; do exercício da ação-reflexão, reflexão-ação, ação-reflexão-ação que emerge de um trabalho integrado entre universidade, redes públicas de Educação Básica e o contexto social existente.

Nesse processo, so estudantes, mais do que aplicarem as teorias apreendidas anteriormente e reproduzirem modelos de aulas de professores experientes observados anteriormente, é posto junto e diante das condições concretas a partir das quais o ensino e a aprendizagem ocorrem. Imerso nessa realidade, os estudantes são convidados a agirem e pensarem (construirem práticas) pedagogicamente para que a docência adquira novas configurações, novas perspectivas e relações para o desenvolvimento e a realização humana.

O estágio é, assim, um espaço de aprendizado crítico-reflexivo da profissão ${ }^{8}$. De acordo com Zabalza (2003), a aprendizagem também é produto da prática do aprendiz, do trabalho solicitado e das condições para realizá-lo. O Estágio não é, por essa ótica, um mero processo de apreensão de "boas práticas de ensino", ou de técnicas e recursos, como muitas vezes se pretendeu incutir na formação

\footnotetext{
8 Partilhamos do pensamento de Silva (2016, p. 35) ao explicar que a "aprendizagem da docência é um processo contínuo que tem início nos primeiros anos de escolarização, estende-se a um processo formal de formação de professores e prossegue ao longo do exercício da docência, numa relação de interdependência entre teoria e prática".
} 
dos professores no Brasil. O estágio é práxis. Nele há potencial para se elevar a qualidade da formação dos professores e, por isso, da educação pública brasileira.

A educação pública brasileira, em especial a partir do governo do Michel Temer $^{9}$, vem sendo exposta a condições de crise, encolhimento, opressão e condições péssimas, quando não irreversíveis, de sobrevivência. Por isso, diríamos que o estágio tem sido desafiado: como contribuir com os estudantes diante de tantas condições desfavoráveis à docência? E, ainda, "Como agir/pensar didaticamente quando não há condições mínimas para a organização de um espaço-tempo educacional que valorize o ensinar e o aprender?". (FRANCO, 2014, p. 10).

Considerando, sobretudo, a realidade exposta, o estágio precisa materializar-se como instrumento de ensino com pesquisa e, portanto, como subsídio para a formação inicial e contínua docente e para a construção da identidade profissional docente, como tem enfatizado Almeida e Pimenta (2014); Pimenta e Lima (2017).

O estágio subsidiado pela pesquisa permite novas possibilidades para se construir um olhar multidisciplinar sobre a docência; para a existência de novas possibilidades de investigação e intervenção no contexto educacional brasileiro. Consubstanciados nos estudos de Vygotsky (2004), entendemos que a pesquisa permite ao indivíduo transcender a zona de desenvolvimento proximal, ampliar a consciência sobre o apreendido e vivido, e transformar a própria prática/formação em verdadeira fonte de crescimento e autoformação ${ }^{10}$. O papel do estágio, por meio da pesquisa, não é levar o estudante a "[...] refletir sobre o que se vai fazer, nem sobre o que se deve fazer, mas sobre o que se faz. [pois] o futuro profissional não pode constituir seu saber-fazer senão a partir do seu próprio fazer" (LIBÂNEO, 2014, p. 89).

Segundo Rios (2014, p. 119), "A pesquisa constitui-se como espaço de partilha de ideias, de levantamento de questões comuns e de descoberta de especificidades e diferenças, portanto favorecedora de diálogo". Por isso, é preciso inserir amplamente a pesquisa com suas múltiplas potencialidades no estágio e na formação docente como um todo. Ainda segundo a autora, a pesquisa é "um trabalho sistemático de investigação da realidade, que parte da constatação do não saber e faz perguntas, pondo-se a caminho para descobrir as respostas" (RIOS, 2014, p. 116-117). Eis o sentido do estágio para que os estudantes possam sentir-se seguros e conhecedores do próprio campo de atuação.

O estágio, assim como a docência, sem a reflexão crítica da prática na prática, quando compreendido e construído sem os mecanismos da pesquisa, da criticidade inerente à Pedagogia e a profissão docente, se fragmenta, se dilui em práticas vazias e opacas de sentido e significado e, acima de tudo, não se constrói uma história e identidade docente de compromisso e emancipação humana.

Estágio e identidade docente se entrecruzam. Não podemos desvincular a identidade docente da história de vida, trajetória de formação e atuação profissional do professor. Diríamos, portanto, que a identidade docente é uma múltipla e autêntica teia de história construída e partilhada de modo a legitimar uma identidade pessoal e profissional própria. Pensar o estágio na formação dos professores

\footnotetext{
9 Triste exemplo é a redução já anunciada pelo governo do Michel Temer de 32\%, em 2018, do orçamento previsto para novos investimentos no Ministério da Educação (MEC) em relação ao ano de 2017.

10 Trata-se de um trabalho de autorreflexão e de autoanálise (NÓVOA, 2009).
} 
é assegurar à identidade docente um lugar importante, de construção, reconstrução e de rememoração da história, e, acima de tudo, de humanização dessa mesma identidade conforme o compromisso da profissão docente com a construção contínua da humanidade.

\section{UNIVERSIDADE, ESTÁGIO SUPERVISIONADO E EDUCAÇÃO BÁSICA: ESPAÇOS DE FORMAÇÃO DE/PARA TODOS}

Os temas universidade11, estágio na formação dos professores e Educação Básica, e o modo como se articulam entre si são, hoje, não diferente de outrora, extensos, complexos e desafiantes quando se trata do debate e da construção da formação docente. Exigem estudos específicos de diferentes áreas, seja da Pedagogia, da Filosofia ou da Psicologia da educação.

A formação dos professores exige que se leve em consideração diferentes elementos que constituem os fios da relação universidade e escola básica, pois a formação docente torna-se, muitas vezes, ineficiente dependendo de como se articulam universidade e redes públicas de Educação Básica. O estágio supervisionado influencia e é fator determinante nessa relação à medida que transita por essas duas instituições e, dependendo da articulação existente entre si, será (ou não) uma experiência significativa e formativa.

Nesta seção, procuramos analisar e problematizar as características e peculiaridades da relação crítico-criativa entre universidade, estágio e Educação Básica, a fim de evidenciar o estágio e a escola básica como espaços de formação de/para todos. Quando trazemos para o debate essa relação, entendemos que o estágio precisa ser pensado e vivido (teoria-prática) com cuidado em todas as etapas para, de fato, chegar até os processos de ensino e aprendizagem que são construídos nas escolas públicas brasileiras a fim de sempre transformá-los. O estágio, por isso, precisa chegar até os alunos dessas instituições e envolvê-los por meio do processo relacional, os estudantes das licenciaturas e os discentes da Educação Básica.

No entanto, quando sublinhamos o estágio como um processo que está diretamente articulado aos processos de ensino e aprendizagem que ocorrem na Educação Básica, precisamos ter os devidos cuidados para não entrar necessariamente no jogo da BNCC e avaliações externas que visam, muitas vezes, oportunizar processos de ensino e aprendizagem enxutos e com foco, notadamente, nas áreas de língua portuguesa e matemática ${ }^{12}$.

Acreditamos que o estágio, por sua natureza político-pedagógica, é um processo contínuo de aprendizado. Quando se pensa nas disciplinas dos cursos de licenciatura sobressai-se a unidade teoria e prática que atribui sentido e significado à formação dos professores. Podemos pensar, assim, que o estágio é sempre uma relação (teoria e prática) da universidade e Educação Básica e vice-

\footnotetext{
11 Nesta seção, optamos pelo vocábulo universidade para fazer referência aos cursos de licenciatura.

12 "Tenho certeza que essa política [PRP] vai, daqui a um tempo, refletir muito nos resultados dos estudantes das proficiências de português, de matemática e de todas as áreas do conhecimento". Trecho do discurso da Maria Cecília Amendola, vice-presidente do Consed, durante cerimônia de lançamento da Política Nacional de Formação de Professores com Residência Pedagógica, out. 2017. Disponível em:<http://portal.mec.gov.br/ultimas-noticias/211-218175739/55921-mec-lanca-politica-nacional-deformacao-de-professores-com-80-mil-vagas-para-residencia-pedagogica-em-2018>. Acesso em: 22 abr. 2018.
} 
versa, com interação, participação, envolvimento e, sobretudo, (trans) formação. O estágio se torna, portanto, relação e nela os estudantes vivem, no tempo histórico e espaço social da universidade, articulado às escolas de Educação Básica, a complexidade da formação e do exercício docente.

Parafraseando Zabalza (2004), o estágio não pode ser entendido como um processo linear, mas deve ser compreendido como círculos progressivos, como se avançasse e retrocedesse para continuar avançando. O que está em questão, portanto, é que não se trata de saudosismo ao modelo do estágio no sentido mais conservador e tradicional de observação, participação e exercício da docência ("regência") para a posterior construção de um relatório, na maioria das vezes, destituído de uma reflexão crítico-filosófica e política. Entretanto, segundo o ponto 2.2.1.1 - Edital Capes nº 6/2018:

A residência pedagógica terá o total de 440 horas de atividades distribuídas da seguinte forma: 60 horas destinadas à ambientação na escola; 320 horas de imersão, sendo 100 de regência, que incluirá o planejamento e execução de pelo menos uma intervenção pedagógica; e 60 horas destinadas à elaboração de relatório final, avaliação e socialização de atividades.

Há, então, uma notória perspectiva de observação, participação e regência expressas sob o discurso de "60 horas destinadas à ambientação na escola; 320 horas de imersão, sendo 100 de regência". Neste caso, qual seria o inédito no PRP propalado pelo Ministério da Educação? Qual a diferença teórico-metodológica do PRP para o estágio no seu sentido mais conservador? O expresso no documento retoma o estágio como mera receita, enumerando os diversos passos que o estágioprofessor deverá seguir em seu caminho para que a aprendizagem da profissão ocorra. Será esse o "novo" caminho?

A teoria ajuda os estudantes a entenderem, perceberem e apreenderem os elementos significativos que perpassam a formação/ação docente como história de vida dos sujeitos envolvidos, sentimentos, desejos e necessidades.

Quando se trata da formação dos professores, a universidade e as escolas básicas são partes de uma mesma realidade e, aliadas e articulando teoria e prática, atribuem sentido e significado à formação e a profissão docente, envolvendo e auxiliando estagiários estudantes na apreensão da profissão. No entanto, infelizmente, notamos no PRP uma sobreposição da prática em relação à teoria. Ao mesmo tempo em que o referido programa diz ter como objetivo estimular articulação entre teoria e prática nos cursos de licenciatura, propõe o fortalecimento do campo da prática ${ }^{13}$.

A teoria se expressa desde o planejamento da ação docente até aos métodos e estratégias de executá-la. Essa teoria atinge e perpassa os afetos, a sensibilidade docente, os valores, as relações estabelecidas e se desdobra, muitas vezes, em uma prática (nova-teoria) que envolve, sensibiliza e mobiliza para a aprendizagem. A teoria-prática, assim, emerge da necessidade interior do indivíduo de aprendizagem.

Por isso, não há como não reconhecer a necessidade da unidade teoria e prática no estágio como práxis. Reduzir o estágio à prática, ou seja, sobrepor a prática à teoria, fazer por fazer, será como os estudantes deixarem de alimentar, ou deixar de existir, o pensamento crítico-criativo de

\footnotetext{
${ }^{13}$ Ver itens 1 e 2 - Edital Capes nº 06/2018.
} 
pensar a própria prática. É a articulação teoria e prática que permite teoria-prática chegarem ao destino, a aprendizagem. É, portanto, a teoria uma resposta interior das práticas.

Importa lembrar ainda que não é papel da teoria na formação dos professores engessá-los ou impor-Ihes ideias ou jeitos de ser/exercer a docência. Ao contrário, a teoria caminha com as práticas docentes. É uma relação intensa e coletiva, e não existiria prática sem a teoria como instrumento que a atribui intencionalidade. É uma relação de mão dupla, da teoria para a prática, da prática para a teoria.

Essa relação evidenciada até aqui entre teoria e prática nos permite pensar a construção dos saberes pedagógicos docentes no estágio. Os saberes pedagógicos têm como fonte uma teoria e prática que vão se completando e transformando. Esses saberes não são a mera apreensão pelos estudantes dos elementos que constituem as práticas, mas é o indivíduo escutando-se, expressandose, construindo e exercendo a docência e entendendo o seu significado. Como explica Franco (2018, p. 60), "um saber implica o exercício de uma prática reflexiva, comprometida, com sentido, com intencionalidade".

Concordando com Sá-Chaves (2018), trata-se da construção de um saber na ação. E, ainda, como diz Franco (2018, p. 50), "a construção de saberes é processo e não produto; é fruto de um trabalho de subjetividade do sujeito; não é algo que se incorpore de fora para dentro; é preciso o papel de reconstrução cognitiva do sujeito". Sendo assim, estamos a enfatizar que o estágio, na relação universidade e escola básica (teoria-prática), deve ser uma experiência que possibilita aos estudantes construirem saberes pedagógicos que atribuam vida às práticas ${ }^{14}$. Isso porque a legitimidade da ação docente é a autenticidade e a autonomia em gestá-la, fazê-la existir no tempo e espaço das salas de aula.

Trata-se também, apoiando-nos em Shulman (2014), da construção do conhecimento pedagógico de conteúdo que, atrelado ao conhecimento pedagógico geral, tornarão apreensíveis os conhecimentos necessários para a aprendizagem dos alunos. Por isso, o estágio, contrário do que propõe o PRP, exige um indivíduo, que cultive um efetivo desejo de aprender, transcender-se, sair de si e estar junto "com" para construir e transformar.

Às vezes não nos damos conta o quanto a universidade pode aprender/ensinar com a escola básica, e vice-versa, quando se trata da formação dos professores. O estágio, deste modo, não é um instrumento somente de ruptura da distância física entre universidade e escola básica, mas, sobretudo, de relação, idas e vindas, conexão que forma, mobiliza e transforma.

\section{CONSIDERAÇÕES FINAIS}

A epígrafe que abre este texto nos permite enfatizar, ainda, que as perguntas, na maioria das vezes, nos possibilitam sempre novas reflexões, diálogos e aprendizagens.

Problematizamos, neste texto, o estágio a partir de algumas perspectivas a fim de encontrar/sugerir, mesmo que provisoriamente, alguns caminhos.

\footnotetext{
${ }^{14}$ A esse respeito, ver: Pimenta (2012).
} 
No tocante ao PRP, a partir da pesquisa documental com foco na análise do edital Capes $\mathrm{n}^{\circ}$ 6/2018, nossos olhares apontam que o "novo", o velho e a secundarização do estágio, como uma atividade crítica, dialética e, portanto, como práxis se entrelaçam no referido Programa. Embora não tenhamos ainda, no campo da formação, estudos que produzam de forma definitiva transformações na prática do estágio, como prática fundamental na formação e na construção da profissionalidade docente, consideramos que um estágio realmente formativo não ocorre por meros decretos. É preciso muito mais, como condições formativas para que movimentos e processos inovadores ocorram nas ancestrais práticas de formação.

Processos inovadores e de mudanças, no campo da formação docente, exigem necessariamente considerar e construir o estágio como um espaço da construção da profissionalização docente e, por isso, como práxis. Entretanto, o estágio, por essa perspectiva, parece não ser suficientemente contemplado no PRP. Precisamos, por isso, problematizar até que ponto o PRP possibilitará aos estudantes dos cursos de licenciatura uma experiência de estágio em uma perspectiva crítica, reflexiva, investigativa e articulada à profissionalização.

Contrários ao modo como o PRP se materializa na prática, atendendo apenas a alguns estudantes, advogamos a importância do estágio supervisionado, que já atende a todos os estudantes, entendido como uma atividade, consubstanciada no conhecimento teórico, na reflexão, por meio do diálogo coletivo, de investigação e intervenção política na realidade experienciada.

Face ao exposto, reiteramos nossa assertiva que o estágio é, acima de tudo, um caminho de formação/aprendizagens a ser percorrido/construído, e não um momento de apreensão de um conjunto extenso de métodos, técnicas ou modelos de aulas. Ou ainda, a mera inserção dos estudantes no contexto escolar superficialmente sem o devido e necessário aprofundamento didático-pedagógico. Daí a defesa de que a Pedagogia e a Didática, quando atreladas ao estágio, possibilitarão a compreensão crítico-reflexiva do contexto escolar com sua diversidade cultural e social, conflitos e fragilidades que, mais do que nunca, exigem uma educação, formação como práxis emancipadora.

Educação como práxis emancipadora exige, necessariamente, uma formação docente que crie, recrie, transforme e encontre caminhos para corresponder às necessidades e desafios postos à docência na contemporaneidade. Entre eles, assegurar a todos o direito a uma educação pública e com qualidade técnico-científica e pedagógica.

O estágio, nesta perspectiva, deve ser instrumento de ensino, pesquisa, ação/transformação e construção de uma sociedade mais humana, solidária e responsável pelo bem comum. Trata-se do estágio como práxis, unidade teoria-prática-transformação (nova ação), como já enfatizado nesta discussão.

É, inclusive, na autenticação da prática pedagógica transformadora que os estudantes constroem seus saberes pedagógicos; um jeito próprio de ser e exercer a docência (identidade docente) e corresponder aos desafios da profissão. O estágio, por isso, é compromisso e ação políticopedagógica que visa (trans) formar não apenas os estudantes, mas também o meio social, cultural e político no qual se concretizam os processos de ensino e aprendizagem. 


\section{REFERÊNCIAS}

1. ALMEIDA, Maria Isabel de; PIMENTA, Selma Garrido. Centralidade do estágio em cursos de Didática nas licenciaturas: rupturas e ressignificações. In: ALMEIDA, Maria Isabel de; PIMENTA, Selma Garrido (orgs.). Estágios supervisionados na formação docente. São Paulo: Cortez, 2014, p. 15-38.

2. ANDRÉ, Marli. Pesquisa, Formação e Prática Docente. In: André, Marli. (org.) O Papel da Pesquisa na Formação e na Prática dos Professores. Campinas, Papirus, 2012, pp. 55-69.

3. ANDRÉ, Marli. A Formação do Pesquisador da Prática Pedagógica. Plurais Revista Multidisciplinar, v. $1, \quad$ n. $1, \quad$ p.30-41, jan./abr. 2016.2 Disponível em: http://dx.doi.org/10.22633/rpge.v21.n.1.2017.9534. Acesso em: 14 jun. 2018.

4. ANASTASIOU, Léa das Graças Camargos. Ensinar, aprender, apreender e processos de ensinagem. In: ANASTASIOU, Léa das Graças Camargos; PESSATE, Leonir. (Org.). Processos de Ensinagem na Universidade. Joinville, SC: UNIVILLE, 2015, p. 15-44.

5. ANFOPE. Anais (Resumos) do XI Seminário Nacional de Formação dos Profissionais de Educação. Rio de Janeiro, ANFOPE, UERJ, 2017. Midia eletrônica (cd), 543 páginas.

6. BRANDÃO, Carlos. O outro ao meu lado: algumas ideias de tempos remotos e atuais para pensar a partilha do saber e a educação de hoje. In: MOLL, Jaqueline (org.). Caminhos da educação integral no Brasil: direito a outros tempos e espaços educativos. Porto Alegre: Penso, 2012, p. 46 - 69.

7. FRANCO, Maria Amélia Santoro. Saber pedagógico ou relação com o saber pedagógico: reflexões conceituais. In: NETO, Alexandre Shigunov; FORTUNATO, Ivan (org.). Saberes pedagógicos: perspectivas \& tendências. São Paulo: Edições Hipótese, 2018. p. 49-65. Disponível em: https://drive.google.com/file/d/16xMpD1Y2p8fmQOKCVQxF-J2Ark6z-jEU/view. Acesso em: 10 maio 2018.

8. FRANCO, Maria Amélia Santoro; PIMENTA, Selma Garrido. Apresentação. In: FRANCO, Maria Amélia Santoro; PIMENTA, Selma Garrido. (Orgs.). Didática: Embates Contemporâneos 3. ed. São Paulo: Edições Loyola, 2014. p. 07- 41.

9. FRANCO, Maria Amélia do Rosário Santoro. Pedagogia e Prática Docente. 1. ed. São Paulo: Cortez, 2012. 
LARROSA, Jorge. La experiência de la leitura: estudos sobre literatura y formación. México, Fondo de Cultura Económica, 2003.

11. LIBÂNEO, José Carlos. O campo teórico e profissional da Didática hoje: entre Ítaca e o canto das sereias. In: FRANCO, Maria Amélia Santoro; PIMENTA, Selma Garrido. (Orgs.). Didática: Embates Contemporâneos 3. ed. São Paulo: Edições Loyola, 2014. p. 43 -73.

12. LIBÂNEO, José Carlos. Diretrizes Curriculares da Pedagogia: imprecisões teóricas e concepção estreita da formação profissional de educadores. Educ. Soc., Campinas, vol. 27, n. 96 - Especial, p. 843-876, out. 2006. Disponível em: http://www.cedes.unicamp.br. Acesso em: 21 abr. 2018.

13. NÓVOA, Antonio. Professores: imagens do futuro presente. Lisboa: Educa, 2009.

14. PIMENTA, Selma Garrido. O Estágio na Formação de Professores: unidade Teoria e Prática? 7. ed. São Paulo: Cortez Editora, 2006.

15. PIMENTA, Selma Garrido. Saber pedagógico: formação de professores: identidade e saberes da docência. In: PIMENTA, Selma Garrido (org.). Saberes pedagógicos e atividade docente. São Paulo: Cortez, 2012, p. 15-34.

16. PIMENTA, Selma Garrido; LIMA, Maria Socorro Lucena. Estágio e docência. 8. ed. São Paulo: Cortez, 2017.

17. PIMENTA, Selma Garrido; FUSARI, José Cerchi; PEDROSO, Cristina Cinto Araújo; PINTO, Umberto de Andrade. Os cursos de licenciatura em pedagogia: fragilidades na formação inicial do professor polivalente. Educ. Pesquisa, São Paulo, v. 43, n. 1, p.15-30, jan./mar. 2017. Disponível em: http://dx.doi.org/10.1590/S1517-9702201701152815. Acesso em: 29 abr. 2018.

18. RIOS, Terezinha Azerêdo. Ampliar o diálogo de saberes para a docência. In: FRANCO, Maria Amélia Santoro; PIMENTA, Selma Garrido. (Orgs.). Didática: embates Contemporâneos 3. ed. São Paulo: Edições Loyola, 2014. p.101-130.

SÁ-CHAVES, Idália. Volta Pedagogia!. In: NETO, Alexandre Shigunov; FORTUNATO, Ivan (Org.). Saberes pedagógicos: perspectivas \& tendências. São Paulo: Edições Hipótese, 2018. p. 36-48. Disponível em: https://drive.google.com/file/d/16xMpD1Y2p8fmQOKCVQxF-J2Ark6z-jEU/view. Acesso em: 10 maio 2018.

SILVA, Maria Vitória da. Dificuldades de leitura de alunos dos anos finais do ensino fundamental em uma escola de zona rural baiana: representações de professores de diferentes disciplinas. 2016. 229f. Tese (Doutorado em Educação) - Universidade de São Paulo - FEUESP, São Paulo. 
21. SHULMAN, Lee S. Conhecimento e ensino: fundamentos para a nova reforma. Cadernos Cenpec, São Paulo, v.4, n.2, p.196-229, dez. 2014. Disponível em: http://dx.doi.org/10.18676/cadernoscenpec.v4i2.293. Acesso em: 09 maio 2018.

22. VIGOSTKY, L. S. Psicologia Pedagógica. 2. ed. Tradução de Paulo Bezerra, São Paulo: Martins Fontes, 2004.

23. ZABALZA, Miguel A. O ensino universitário: seu cenário e seus protagonistas. Porto Alegre: Artmed, 2004.

\section{Osmar Hélio Alves Araújo}

Doutor em Educação, pela Universidade Federal da Paraíba (UFPB). Mestre em Educação, pela Universidade Federal do Ceará (UFC). Professor Adjunto A da Universidade Federal do Sul e Sudeste do Pará (Unifesspa) - Instituto de Ciências Humanas - Faculdade de Ciências da Educação (FACED). Integra o grupo de pesquisa cadastrado junto ao CNPq: Formação Docente, História e Política Educacional (GPFOHPE - UFC). Reúne experiência como professor da Educação Básica (Educação Infantil ao Ensino Médio), dos diversos cursos de licenciatura, supervisor educacional e professor formador dos professores da Educação Básica. Atualmente, tem se dedicado a estudos e pesquisas com foco na Pedagogia, Didática, estágio supervisionado, formação de professores; gestão, coordenação e organização pedagógica da escola básica

\section{Elcimar Simão Martins}

Doutor e mestre em Educação pelo Programa de Pós-Graduação em Educação da Universidade Federal do Ceará. Professor Adjunto A do Instituto de Ciências Exatas e da Natureza (ICEN) e do Mestrado Acadêmico em Sociobiodiversidade e Tecnologias Sustentáveis (MASTS), da Universidade da Integração Internacional da Lusofonia Afro-Brasileira (UNILAB). Membro dos Grupos de Pesquisas sobre Formação do Educador (GEPEFE/USP), Educação e Cooperação Sul-Sul (Eloss/Unilab) e Formação Docente, História e Política Educacional (GPFOHPE/UFC).

\section{Como citar este documento}

ARAÚJO, Osmar Hélio Alves; MARTINS, Elcimar Simão. Estágio curricular supervisionado como práxis: algumas perguntas e possíveis respostas. Reflexão e Ação, Santa Cruz do Sul, v. 28, n. 1, jan. 2020. ISSN 1982-9949.

Disponível em: <https://online.unisc.br/seer/index.php/reflex/article/view/12902>. Acesso em: doi:https://doi.org/10.17058/rea.v28i1.12902. 